\title{
RESILICENTRO - CENTRO DE PESQUISAS TECNOLÓGICAS CLIMÁTICAS
}

\author{
VIANA, Shaiane \\ Unifor - Universidade de Fortaleza, e-mail: shaiane@edu.unifor.br \\ NAZARETH, Samuel \\ Universidade Presbiteriana Mackenzie, e-mail: bmnsamuel@gmail.com \\ BECKER, Newton \\ UFC - Universidade Federal do Ceará, e-mail: arqnewton@yahoo.com
}

\begin{abstract}
RESUMO
O presente artigo é resultado do trabalho final de graduação do curso de arquitetura e urbanismo. A dualidade dos fenômenos climáticos (chuvas extremas e fortes estiagem) no Ceará, Brasil, resulta em ocorrências na maioria dos municípios no semiárido do estado. Como exemplo disso, tem-se o município de Assaré que, em 2016, abriv estado de emergência devido à forte estiagem e, em abril de 2017, tornou a abrir por causa das fortes chuvas que atingiram o açude da região e alagaram a cidade, deixando mais de 40 desabrigados. Visto o despreparo para lidar os fenômenos, propõe-se um Centro de Resiliência para convivência com as mudanças climáticas no semiárido do Ceará. Diante dos acontecimentos relatados, averiguouse a necessidade de alternativas para conviver permanentemente com fenômenos climáticos extremos, criando-se, então, o Resilicentro, um espaço destinado à realização de pesquisas e demonstração de tecnologias para melhorar a convivência social com as condições climáticas, hídricas, sociais e ambientais do Semiárido do Ceará. Sendo uma proposta para uma unidade de pesquisa integrante do Ministério da Ciência, Tecnologia, Inovações e Comunicações (MCTIC), a construção do centro baseou-se na metodologia utilizada pela Organização das Nações Unidas para a Educação, a Ciência e a Cultura (UNESCO), sobre mudança climática.
\end{abstract}

Palavras-chave: Arquitetura, Resiliência, Mudanças Climáticas

\begin{abstract}
The present article is the result of the final course of graduation of the course of architecture and urbanism. The duality of climatic phenomena (extreme rains and severe drought) in Ceará, Brazil, results in occurrences in most of the municipalities in the state's semi-arid region. As an example, there is the municipality of Assare that in 2016 opened a state of emergency due to the strong drought and, in April 2017, opened again because of the heavy rains that reached the weir of the region and flooded the city, leaving more than 40 homeless. Given the lack of preparation to deal with the phenomena, it is proposed a Resilience Center to coexist with climatic changes in the semi-arid situations of Ceará. In view of the reported events, it was verified the need for possible alternatives to live permanently with extreme climatic phenomena, creating the Resilicentro, a space for conducting research and demonstration of technologies to improve social coexistence with the climatic, water, social and environmental conditions of the semi-arid region of Ceará. As a proposal for an integrated research unit of the Ministry of Science, Technology, Innovations and Communications (MCTIC), the construction of the center was based on the methodology used by the United Nations Educational, Scientific and Cultural Organization (UNESCO) on climate change.
\end{abstract}

Keywords: Architecture; Resilience; Climate changes.

VIANA, S.; BERTRAND, S.; BECKER, N. Resilicentro - Centro De Pesquisas Tecnológicas Climáticas. In: SIMPÓSIO BRASILEIRO DE QUALIDADE DO PROJETO NO AMBIENTE CONSTRUÍDO, 6., 2019, Uberlândia. Anais... Uberlândia: PPGAU/FAUeD/UFU, 2019. p. 1618-1626. DOI https://doi.org/10.14393/sbqp19146. 


\section{INTRODUÇÃO}

A ideia deste trabalho iniciou-se após o relato do noticiário sobre 0 rompimento da barragem do Rio Doce na cidade de Mariana/MG em novembro de 2015, o qual resultou em 19 mortes e em um significativo número de pessoas desabrigadas. A imagem dos que sofreram com o ocorrido foi a mais impactante, principalmente daqueles que ainda se encontravam vivos. Foram eles os responsáveis por inquietar vários questionamentos: Para onde iriam? Poderiam voltar para a cidade de origem novamente? E, até lá, como poderiam, enfim, se recompor?

Em meio às construções que se transformaram em barro e aos rios em lama, a fuga das pessoas desalojadas foi solucionada em ginásios esportivos das cidades vizinhas de Mariana. Mais uma vez, a terrível cena de famílias amontoadas recebendo doações em um grande ginásio, vazio de desconforto, tornou a inquietar.

Essa inquietude revelou o pensamento do quão estamos despreparados para lidar com qualquer tipo de cataclismos no país, refletindo, então, na escolha do tema para o trabalho de conclusão de curso.

Inicialmente, a ideia era trabalhar com abrigos emergenciais que pudessem ajudar a recompor a vida de famílias logo após as catástrofes, mas com diferenças em relação ao caso da cidade de Mariana, apresentando uma abordagem para a realidade dos desastres naturais relacionados ao estado do Ceará sobre seca e chuva, os quais estão cada vez mais recorrentes no cenário nacional. É possível averiguar esse fato com a publicação da Organização das Nações Unidas no Brasil: "Brasil está entre os 10 países com maior número de afetados por desastres nos últimos 20 anos." (ONUBR, 2015). Números retirados do segundo relatório das Nações Unidas para a Redução de Desastres (UNISDR) que avalia catástrofes relacionadas a fenômenos climáticos no mundo e seus danos para a população. De acordo com a divulgação desse relatório, entre os anos de 1995 a 2015, 51 milhões de brasileiros foram impactados por catástrofes, sendo $90 \%$ desses relacionados com o clima.

Como já mencionado, a realidade do Nordeste do país não é diferente. A dualidade dos fenômenos climáticos (chuvas extremas e fortes estiagem) no Ceará resulta em ocorrências na maioria dos municípios presentes no semiárido do estado. Como exemplo disso, tem-se o município de Assaré que, em 2016, abriv estado de emergência por conta da forte estiagem e, em abril de 2017, tornou a abrir por causa das fortes chuvas que atingiram o açude da região e alagaram a cidade, deixando mais de 40 desabrigados.

Visto o despreparo lidar com a realidade dos fenômenos climáticos, a proposta inicial refratou. Ao invés de um abrigo emergencial, propõe-se um estudo sobre soluções para uma comunidade resiliente diante das mudanças climáticas para situações do semiárido do Ceará. Pois, diante dos acontecimentos relatados, averiguou-se a necessidade do estudo de possíveis formas de conviver permanentemente com fenômenos climáticos extremos.

Em âmbito mundial, foram buscados projetos de referência em áreas que sofreram com desastres naturais. Ao serem analisados, foi possível verificar que grande parte foi resultado proveniente de projetos emergenciais de aspectos temporários, que possuíam a função de suprir a necessidade da população 
afetada até que esta conseguisse se recompor. Notou-se, então, que esses projetos têm a intenção de suprir a urgência da realidade nos casos de desastres, pois tendem a ser de rápida construção, leves, de fácil manuseio e montagem. No entanto, a característica emergencial deixa a desejar na adaptação da comunidade com o risco do local conforme citam Boano e Zetter:

Iniciativas de reconstrução pós-desastres geralmente se concentram na construção de abrigos. Elas raramente se focam em recuperar uma noção de espaço e local público que é crucial para reconstrução de longo termo da população afetada. (BOANO e ZETTER, 2010)

De forma a atender essa carência, a pesquisa tende a propor soluções para adaptabilidade permanente da comunidade na situação específica do semiárido do Ceará que, sem preparo, sofreu com as fortes chuvas e alagamentos no ano de 2017. Trata-se não apenas de uma intervenção temporária, mas de uma intervenção que prepare a comunidade local para conviver com a nova realidade e que reduza a sua vulnerabilidade diante dos impactos das mudanças climáticas. Isso se torna possível através da adoção de uma infraestrutura verde, a qual tem o poder de mitigar os efeitos da chuva e da seca, e das estratégias do conforto ambiental aplicado à arquitetura a fim de tornar viável a convivência com a dualidade desses fenômenos. Uma abordagem replicável para o planejamento de infraestrutura futura, de modo que ele maximize a resiliência social e ecológica do semiárido.

\section{METODOLOGIA}

A construção deste estudo teve como base a metodologia utilizada no curso da Organização das Nações Unidas para a Educação, a Ciência e a Cultura (UNESCO), figura 1, sobre educação em mudança climática e desenvolvimento sustentável (EMCDS). De maneira adaptada, as etapas deste trabalho se dão em três (3) fases que, subdivididas, resultam em seis sub-etapas: i) Compreensão: i.i) definição do problema; e das principais questões pertinentes a este, considerando a estrutura, a delimitação e as limitações do estudo pretendido, bem como suas principais variáveis; i.ii) revisão da literatura para percepção do que foi produzido de caráter

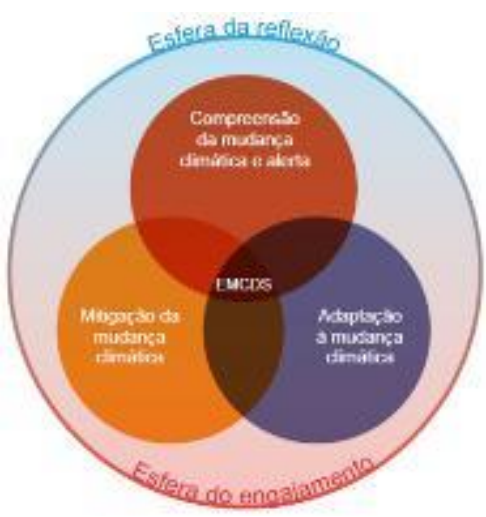

Figura 1 - Dinâmica da transformação

Fonte: UNESCO, 2014 teórico e técnico relacionado ao tema; ii) Mitigação: ii.i) visita técnica na zona escolhida para realização de entrevistas com os afetados pelos intemperes, registros fotográficos e avaliação do local; ii.ii) coleta e análise de dados adquiridos de base públicas ou de secretárias e órgãos do Ceará, analisados em softwares de georreferenciamento, modelagem e simulação; iii) Adaptação: iii.i) referencial projetual e conceitual de testes e elementos já utilizados para embasamento de estratégias do projeto adaptativo; iii.ii) proposta projetual para desenvolvimento definitivo do projeto arquitetônico e paisagístico. 


\section{RESULTADOS E DISCUSSÃO}

As possibilidades de intervenção são múltiplas para a cidade de Assaré-Ce. Com a finalidade de atender às demandas de maneira mais holística e eficaz, realizou-se um Plano Geral de Infraestrutura Verde, a qual se baseia em três princípios-chave para a manutenção da vida em sociedade, sendo eles: cultura, controle e provimento. Tendo como base esse tripé e o conhecimento adquirido através do diagnóstico, o processo de estruturação da proposta ocorreu de acordo com os seguintes passos: foram elencadas as possíveis funções da infraestrutura proposta, desde as mais gerais, como a de transportar e divertir, às mais específicas, como a de coleta e filtragem da água. Para viabilizar tais funções, são necessários elementos que compõem a infraestrutura dos lugares da cidade, como ruas, praças, açudes e riachos.

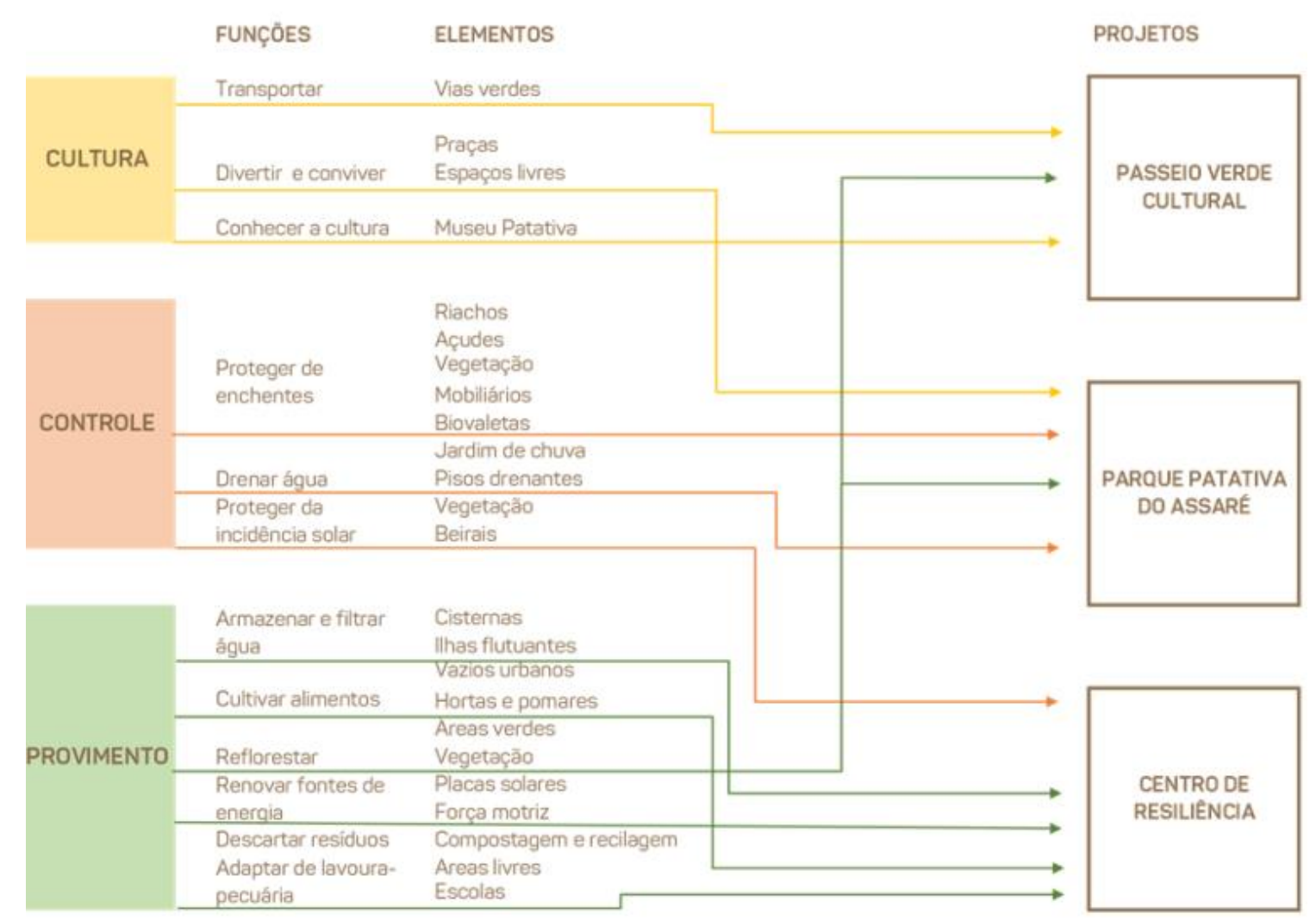

Figura 2 - Plano IEV

Fonte: AUTORES, 2018

Para atender às demandas de maneira mais eficaz, realizou-se um Plano Geral de Infraestrutura Verde, que se baseia em três princípios-chave para a manutenção da vida em sociedade, sendo eles: cultura, controle e provimento. Os projetos resultantes que traduzem e expressam demandas são três: Passeio Verde Cultural, o qual será apenas uma proposta deste trabalho; Parque Patativa do Assaré, que será apresentado soluções; e o Centro de Resiliência, ponto central para responder às demandas por resiliência, apelidado de Resilicentro. 


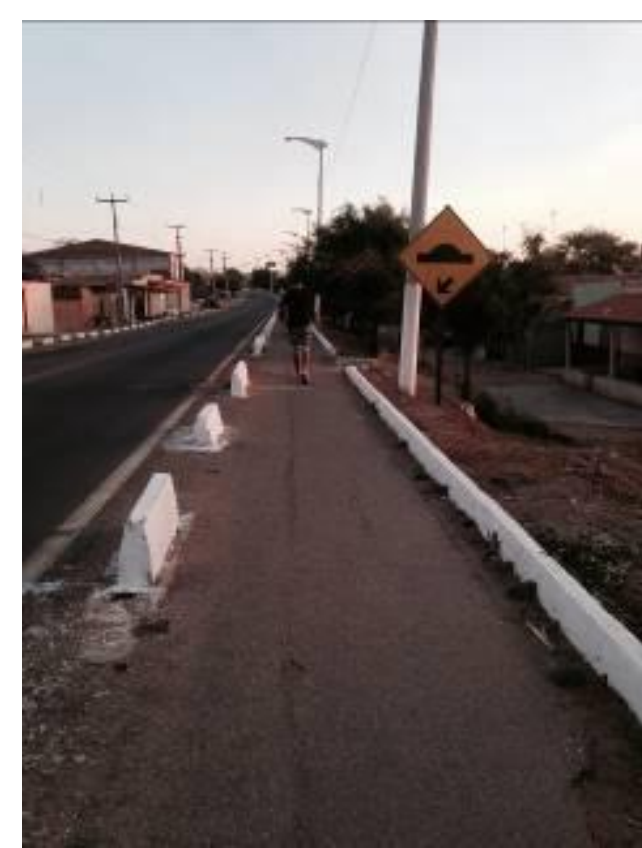

Figura 3 - Acostamento da Cidade de Assaré

Fonte: AUTORES, 2018

Passeio Cultural Verde: Em visita à cidade, foi possível verificar que a população não possuía um local de lazer e nem que promovesse a realização de atividades físicas. Observou-se, também, que o acostamento da rodovia $C E$, que dá acesso à cidade, estava sendo utilizado como área para caminhadas. Isto posto, deixa-se como proposta uma rede de passeios verdes que interligam os pontos culturais da cidade e a massa arbórea existente, a fim de propagar o microclima sombreado da região em áreas caminháveis.

Parque Patativa do Assaré: Conforme o diagnostico desta pesquisa, a cidade de Assaré vive em cota abaixo dos açudes do seu entorno e no sentido da jusante de suas respectivas nascentes. Desta forma, propõe-se um parque às margens dos leitos dos rios em que a vegetação seja implantada com uma significativa movimentação de terra para o lado contrário ao da urbanização consolidada da cidade. Isto para que, em caso de rompimento de um novo açude, a água venha a atingir, primeiramente, o parque, onde as árvores poderão controlar a velocidade da água, possibilitando que esta chegue com menos força às casas.

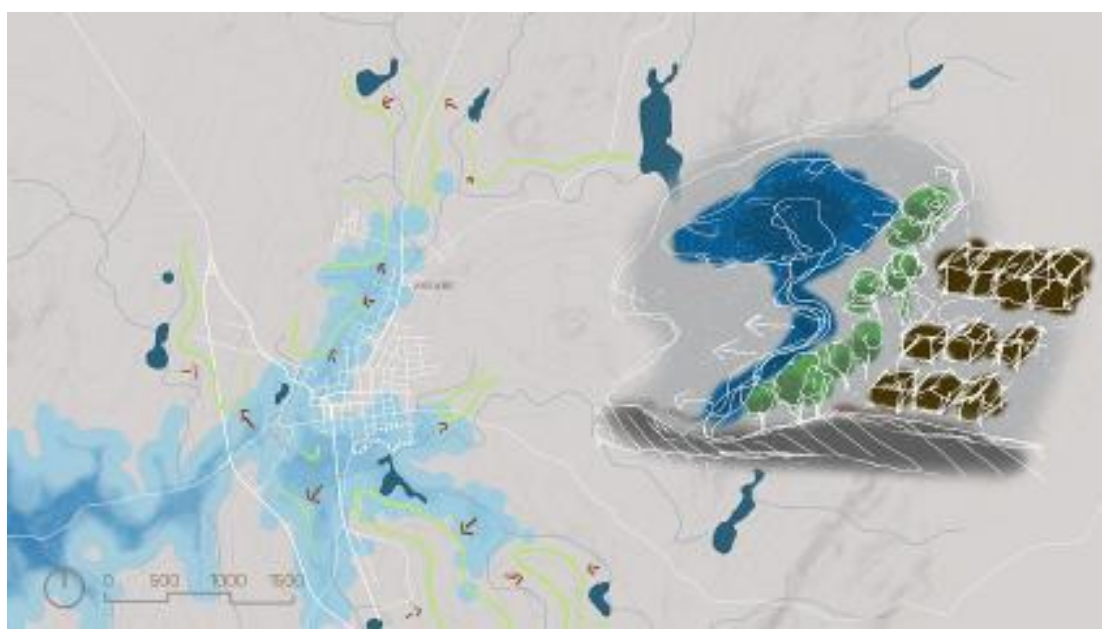

Figura 4 - Proposta Parque Patativa do Assaré Fonte: AUTORES, 2018
O parque em questão, além de servir para situações

emergenciais de enchentes, pode vir a controlar as necessidades da cidade relacionadas à retenção de água da chuva por meio dos elementos de infraestrutura

verde, como jardins de chuva, biovaletas e o próprio açude (atuando como uma bacia de retenção); propagação de microclima arbóreo e a biodiversidade com implantação árvores da caatinga resistentes à seca, sendo elas: Algaroba (Prosopis juliflora), Juazeiro (Ziziphus joazeiro), Umbuzeiro (Spondias tuberosa), Maracujá do mato (Passiflora cincinnata) e Araticum (Annona ssp). Então, delimitou-se uma área de detalhe do parque para que pudesse instalar 0 outro projeto resultante do plano de infraestrutura verde - IEV. 


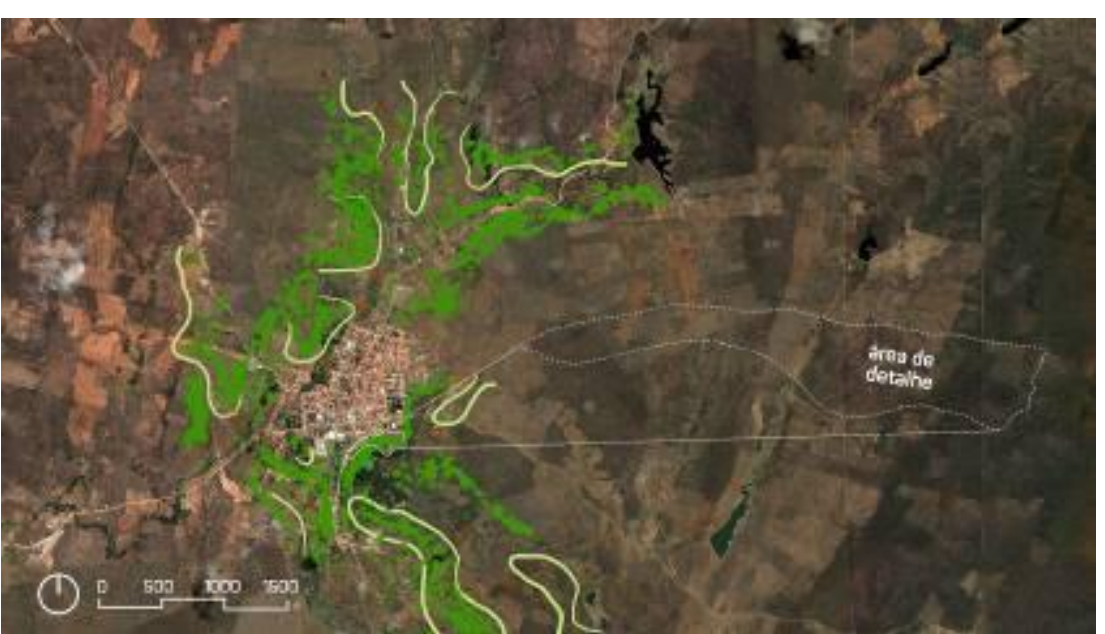

Figura 5: Área de intervenção do Resilicentro

Fonte: AUTORES, 2018
Centro

de

Resiliência:

Espaço destinado à realização de pesquisas e à demonstração de tecnologias sustentáveis para melhorar convivência social com as condições climáticas, hídricas, sociais e ambientais do semiárido

brasileiro. Decidiu-se situar o Resilicentro entre um centro de pesquisas e um centro comunitário, onde a população, auxiliada de profissionais, poderá encontrar um lugar para retomar suas atividades que estejam relacionadas à agricultura e à bioconstrução. O terreno pertence à Prefeitura de Assaré-CE, situa-se às margens de um açude, que está na área de detalhe do Parque.
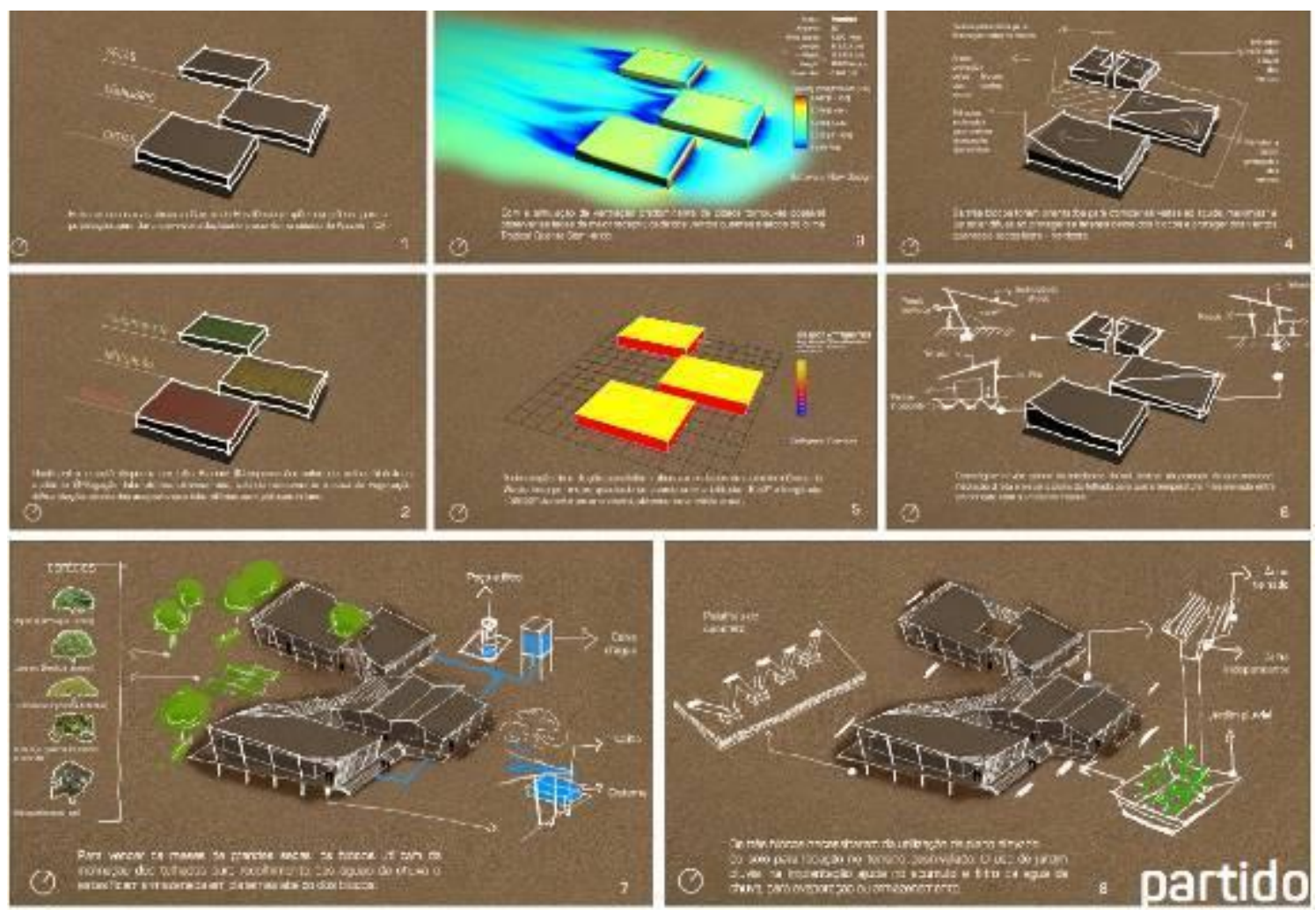

Figura 6: Partido do Resilicentro

Fonte: AUTORES, 2018

Resilicentro está disposto em três blocos:

I) Compreensão: salas de aula, biblioteca e sala de conferências, encontra-se na cota mais alta do terreno, estando livre de inundações; 
II) Mitigação: laboratórios, almoxarifado e cactário, situa-se no meio do terreno e, para que não haja movimentação de terra, sua fundação é semienterrada. Assim, caso chova, a água não ocasionará prejuízos à edificação;

III) Adaptação: Atividades adaptativas e a laboratórios com práticas in loco, este bloco encontra-se na cota mais baixa, onde sua fundação é toda elevada, com presença de escadarias e rampas e, possuindo, ao final dele, um mirante para o açude.

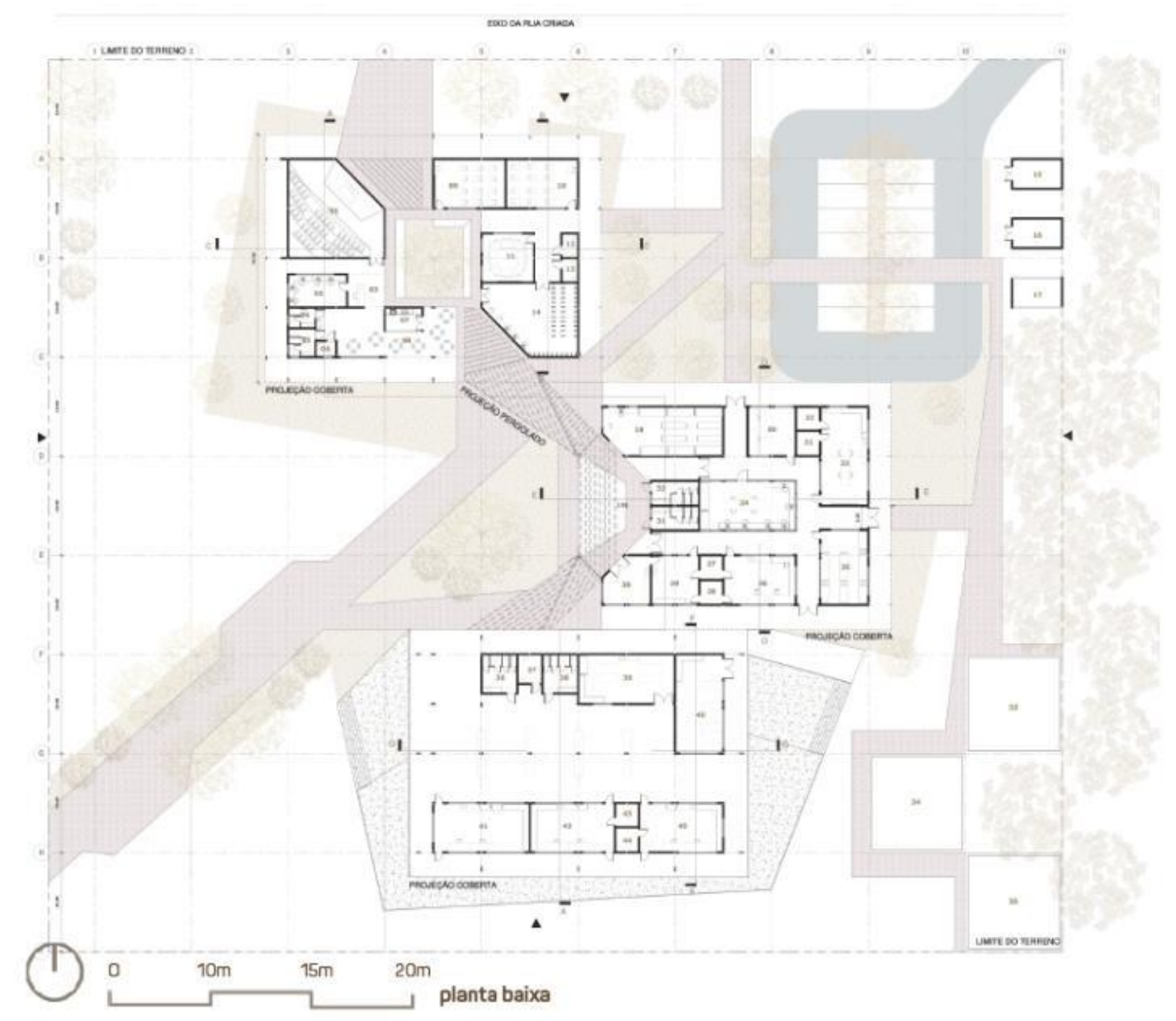

Figura 7: Planta baixa

Fonte: AUTORES, 2018

A dinâmica do equipamento arquitetônico funciona como um catalizador entre os cenários presentes na cidade de Assaré - CE. Em épocas de seca as cisternas cumprem em baixo sua função de armazenamento de água, em épocas de chuvas pontuais as cisternas recebem a água vinda das calhas dos telhados (sistema pluvial) e as biovaletas evaporam parte da água e outra parte é infiltrada no solo, nos casos das enchentes as base elevada da estrutura passa a proteger o equipamento de uma inundação, prevenindo futuros desastres. E assim cria-se um ciclo de adaptação aos fenômenos climáticos presente na cidade. 


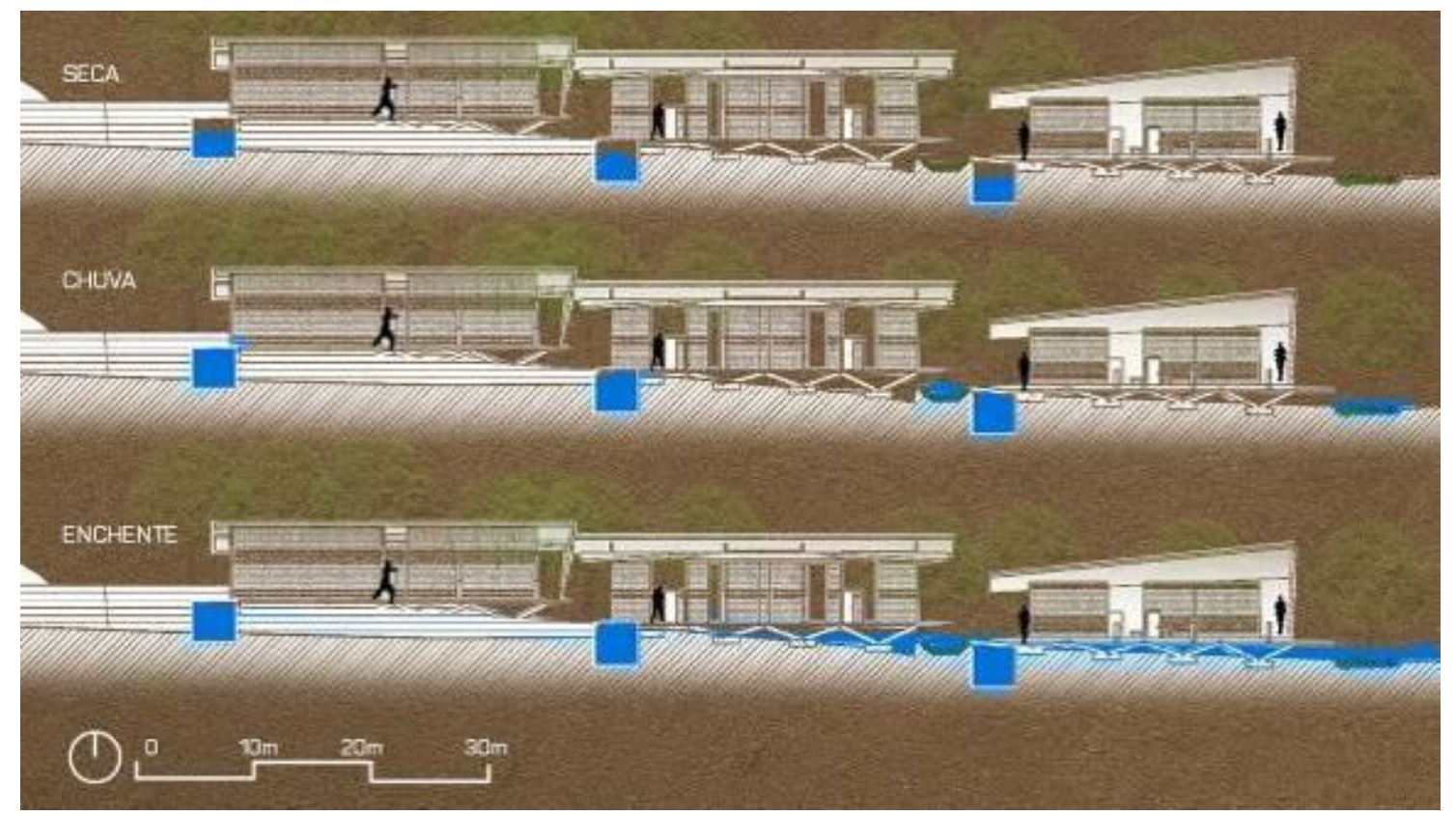

Figura 8: Cenários de Assaré - CE

Fonte: AUTORES, 2018

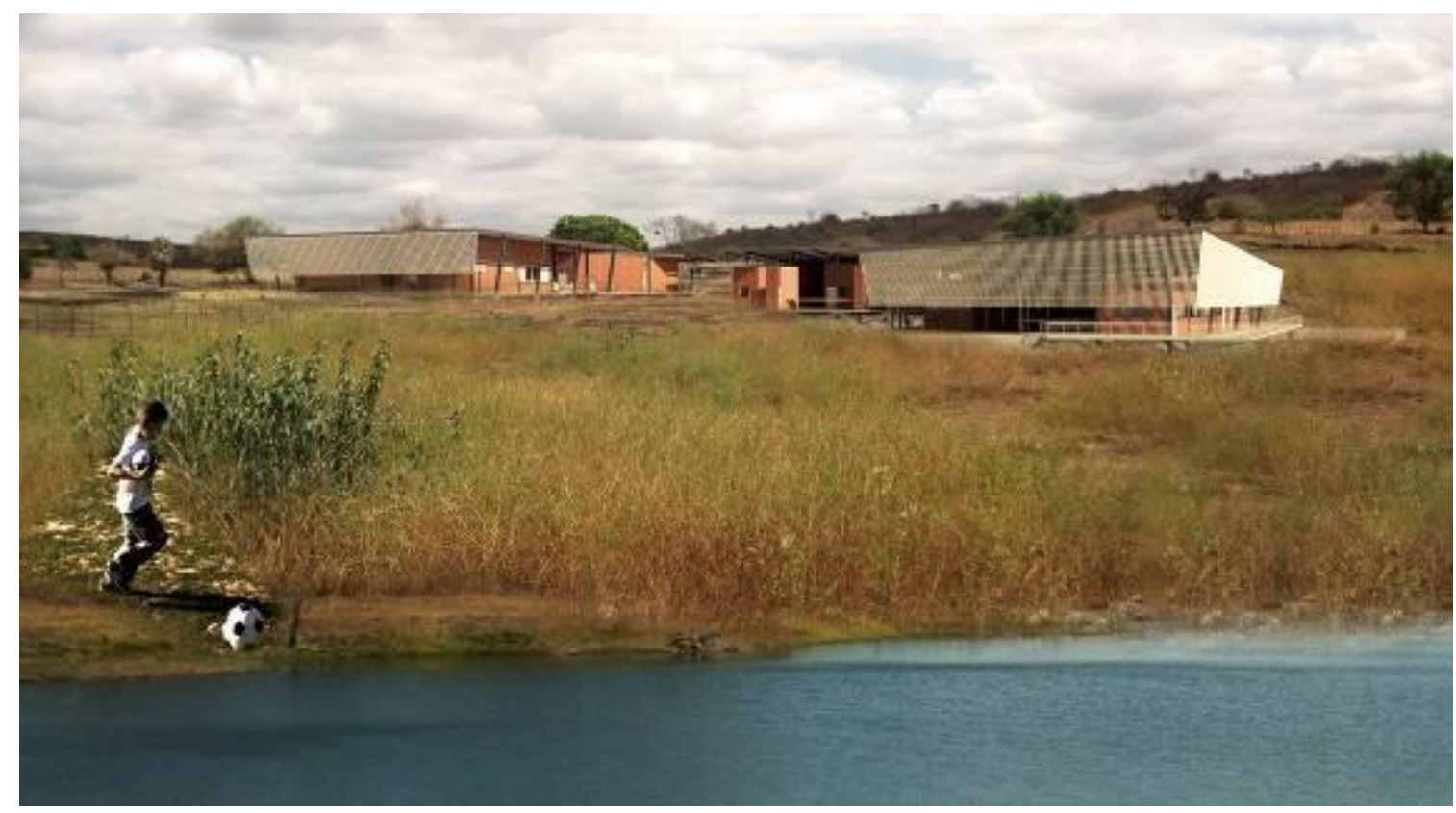

Figura 9: Resilicentro

Fonte: AUTORES, 2018

\section{CONSIDERAÇÕES FINAIS}

Este trabalho é uma partícula de uma pesquisa que está em fase inicial, podendo se estender. Caracteriza-se como uma busca por melhores armazenamentos de água no semiárido e melhores controles de fenômenos do clima, tendo em vista a carência de institutos que lidam com as questões climáticas no cenário do estado do Ceará. Espera-se que, mesmo em escala da cidade local, a proposta do Resilicentro tenha demonstrado que, com estratégias básicas arquitetônicas e com a ajuda da tecnologia, é possível conviver em conforto com o ambiente edificado e o ambiente natural. Dessa 
maneira, espera-se ter respondido com arquitetura, urbanismo, conforto e paisagismo o problema da cidade de Assaré-CE.

\section{AGRADECIMENTOS}

Agradeço aos professores Newton e Amando por terem elevado o nível dessa pesquisa, ao Samuel Bertrand por não me deixar desistir entre um artigo e outro e também à Marina Frota, pois sem o seu equipamento, esse artigo não estaria finalizado.

\section{REFERÊNCIAS}

BOANO, C.; ZETTER, R. Space and place after natural disasters and forced displacement. In: LIZARRALDE, JOHNSON, DAVIDSON; Rebuilding after disasters: from emergency to sustainability. London: Taylor and Francis, 2010. p. 206- 230.

ONUBR. ONUBR Nações Unidas no Brasil. ONU Brasil está entre os 10 países com maior número de afetados por desastres nos últimos 20 anos, 2015. Disponível em: <https://nacoesunidas.org/onu-brasil-esta-entre-os-10-paises-com-maiornumero-de-afetados-por-desastres-nos-ultimos-20-anos/>. Acesso em: 15 Agosto 2018.

UNESCO. Mudança climática em sala de aula: curso da UNESCO para professores secundários (fundamental Il e ensino médio) sobre educação em mudança climática e desenvolvimento sustentável (EMCDS), Brasília, 2014. 